\title{
(4)
}

Revista Mexicana de Derecho Constitucional

Núm. 40, enero-junio 2019

\section{Ley de Seguridad Interior y militarización}

\section{Homeland Security Law and Militarization}

\section{Jaime CÁRDENAS GRACIA*}

RESUMEN: El ensayo expone las razones que impulsan al gobierno y a otros actores a aprobar una ley de seguridad interior para México. Se describen y cuestionan algunas iniciativas de ley presentadas. Se proporcionan argumentos para sostener que la seguridad en un Estado constitucional de derecho corresponde a la autoridad civil y no a las fuerzas armadas. En las conclusiones, proponemos reformas constitucionales para impedir la militarización del país.

Palabras clave: Ley de Seguridad Interior; militarización; geopolítica.
ABSTRACT: This paper explores the reasons why the government and other political actors want a new interior security law in Mexico approved. Some initiatives of this law are described and critically examined. It puts forth arguments supporting the view that security is a responsibility of civilian authorities in a Constitutional Rule of Law and not of the armed forced. The conclusions argue for constitutional reforms that will avoid the militarization of the country. Keywords: Interior Security Law; Militarization; Geopolitics.

* Investigador de tiempo completo en el Instituto de Investigaciones Jurídicas de la UNAM (jaicardenas@aol.com). 
SUMARIO: I. El contexto de la militarización y de la demanda de aprobación de una ley de seguridad interior. II. Algunas iniciativas de ley presentadas en materia de seguridad interior. III. ¿Por qué la seguridad en un Estado constitucional de derecho corresponde a la autoridad civil y a los ciudadanos, y no a las fuerzas armadas? IV. Conclusiones.

\section{EL CONTEXTO DE LA MILITARIZACIÓN Y DE LA DEMANDA DE APROBACIÓN DE UNA LEY DE SEGURIDAD INTERIOR}

El objetivo fundamental de este ensayo y su hilo conductor es que la política de seguridad de nuestro país se dirige a la integración militar y de seguridad de México a la órbita de las decisiones norteamericanas. La soberanía de una nación tiene que ver fundamentalmente con el control de su fuerza pública y militar, y México pierde a pasos acelerados el control pleno sobre sus fuerzas de seguridad a favor de la integración de América del Norte y de los Estados Unidos para el provecho y beneficio de ese país.

En este artículo, sostenemos las siguientes tesis:

1) Nuestros adversarios han sido siempre los intereses geopolíticos del gobierno norteamericano.

2) El gobierno de Estados Unidos ha intentado engañarnos señalando que nuestros enemigos, que en parte lo son, pero además de ellos, residen en el terrorismo y el crimen organizado.

3) La lucha contra las drogas y el crimen organizado ha impuesto a México enemigos que antes no tenía y, de además ha incrementado los índices de violencia en el país, la letalidad por el empleo de las armas y las violaciones a los derechos humanos.

4) La militarización del país, que para sectores gubernamentales (incluidas las fuerzas armadas) fue resultado de la inoperancia de las autoridades de seguridad pública, pero que constituye una violación a distintos preceptos de la Constitución —artículos 21 y 129 - , nos conduce a la utilización de las fuerzas armadas en contra de nuestra población, y a situaciones políticas autoritarias en parte superadas en el país.

5) Socialmente, existe una cultura de la impunidad e incentivos para dedicarse al crimen, porque el Estado ha descuidado la educación pública con valores cívicos como motor de movilidad social. 
6) Tenemos un modelo económico neoliberal que produce cada vez más pobres, sin perspectivas de vida, que son arrastrados por la lógica neoliberal a la precariedad laboral y salarial. ${ }^{1}$

7) En concreto, la crisis de inseguridad es política y de gobernabilidad, y no es acertado el diagnóstico que criminaliza a la población.

8) Los recursos humanos (en particular las policías) están subordinados de hecho a las fuerzas armadas ahí donde éstas tienen presencia, y están mal remunerados y mal capacitados; son un reflejo de la problemática estructural nacional y local.

9) Para atacar el problema de la inseguridad, debemos replantear la independencia de las policías del ejército y emplear los recursos económicos, que son insuficientes y mal distribuidos, en beneficio de las policías, y con una reducción significativa de los recursos a favor del ejército.

10) La buena o mala designación o elección de autoridades locales influye en su incapacidad o, incluso, colusión con el crimen organizado nacional, regional y municipal.

11) Proponemos el regreso de las fuerzas armadas a sus cuarteles en un plazo perentorio para satisfacer el mandato del artículo 129 constitucional.

12) Los tres órdenes de gobierno deben reasumir sus competencias en materia de seguridad pública.

13) En caso de imposibilidad de esa reasunción de responsabilidades, previas a las responsabilidades que correspondan, se deben iniciar en las entidades federativas los procedimientos de suspensión de derechos y garantías conforme al artículo 29 constitucional o el previsto en el primer párrafo del artículo 119 de la ley fundamental, que son las vías constitucionales que permiten la intervención de las fuerzas armadas en un marco de respeto a la división de poderes y al federalismo.

14) Proponemos la invalidez de los acuerdos interinstitucionales en materia de seguridad firmados con el gobierno de los Estados Unidos, por ser contrarios al artículo 76, fracción I, párrafo segundo, de la Constitución. ${ }^{2}$

1 Cárdenas Gracia, Jaime, El modelo jurídico del neoliberalismo, México, FloresUNAM, 2016; id., Del Estado absoluto al Estado neoliberal, México, UNAM, 2017.

2 Consideramos que el artículo 2o., fracción II, de la Ley sobre Celebración de Tratados, que, entre otros, se refiere a los acuerdos interinstitucionales, es inconstitucional, 
15) Proponemos una comisión de la verdad, electa por los ciudadanos, que investigue las violaciones a los derechos humanos motivadas por la presencia de las fuerzas armadas en tareas de seguridad pública.

16) Insistimos en la necesaria profesionalización, capacitación y dignificación de las policías del país en los tres órdenes de gobierno.

Para problematizar nuestras tesis, hacemos a los lectores los siguientes cuestionamientos:

1) ¿Es la militarización del país la solución para resolver los problemas de inseguridad?

2) ¿La militarización conduce a la reducción de la democracia, las libertades y los derechos humanos?

3) ¿Cuál ha sido la experiencia de la militarización en otros países?

4) ¿Qué consecuencias produce la militarización en el Estado constitucional de derecho, en la democracia, en la división de poderes, en el régimen republicano y en las decisiones de la Suprema Corte de Justicia de la Nación?

5) ¿El Poder Legislativo ha defendido la seguridad pública profesional y se ha resistido a los embates de presión geopolítica de los Estados Unidos, que estimula el empleo de las fuerzas armadas en tareas de seguridad?

6) ¿Realmente cuántos estados y municipios tienen problemas de inseguridad al grado máximo?

7) ¿La presencia de las fuerzas armadas en los territorios del país inhiben al crimen organizado o, por el contrario, promueven la violencia y la afectación a los derechos humanos?

8) ¿Cuánto costarían policías capacitados con relación al costo de las fuerzas armadas si éstas estuvieran en sus cuarteles?

Frente a la pretensión inconstitucional en México para aprobar una ley de seguridad interior, ${ }^{3}$ proponemos las siguientes alternativas de solución:

porque obliga al Estado sin que el Senado ratifique estos acuerdos, violándose con ello disposiciones como el artículo 49 constitucional, en materia de división de poderes.

Este artículo fue enviado para dictamen en noviembre de 2017 antes de la aprobación de la Ley de Seguridad Interior y posterior publicación en el Diario Oficial de la Federación el 21 de diciembre de 2017. 
1) Fortalecer a las policías.

a) Plantear un sistema de profesionalización policial nacional.

b) Profesionalización de los cuerpos policiacos locales.

c) Controles de confianza previos al ingreso al servicio policial.

d) Consolidación de una academia de policía de calidad mundial para la capacitación policial y la educación en general.

e) Salarios e incentivos suficientes para la carrera policial.

f) Crear un registro nacional de policías.

g) Alcanzar estándares internacionales en número de policías por cada mil habitantes, proceso que debe ir acompañado de agentes del Ministerio Público profesionales y suficientes.

2) Fortalecer los criterios para la elegibilidad de los representantes populares locales y federales, y de autoridades en general.

a) Establecer como requisito de elegibilidad constancias y pruebas de vida de no antecedentes penales.

b) Exigir a los partidos políticos mayor rigor en la elección de candidatos y autoridades locales, e ir constituyendo o consolidando, según sea el caso, un servicio civil de carrera municipal, estatal y federal.

3) Fortalecer a los municipios y a los estados a través de recursos económicos suficientes para respaldar la infraestructura y al personal policial.

a) Descentralizar municipalmente el gasto en materia de seguridad pública.

b) Identificar cuántos municipios existen con alto índice de criminalidad.

c) Verificar la política financiera en materia de seguridad pública de los últimos años.

A nivel de la política interna, los presidentes de la República en los últimos sexenios, sobre todo Calderón y Peña, han buscado centralizar competencias, afectando a los otros dos niveles de gobierno - el estatal y municipal-, para aumentar su poder político frente y en contra de los poderes horizontales y verticales establecidos en la Constitución. Prueba de ello son las múltiples reformas constitucionales que se han emprendido en estos años para lograr ese objetivo. 
Sostenemos en este ensayo que la militarización del país no es el camino de México. En agosto de 2011, la Universidad Nacional Autónoma de México (UNAM) y el Instituto Iberoamericano de Derecho Constitucional publicaron un interesante documento titulado "Elementos para la construcción de una política de Estado para la seguridad y justicia en democracia". ${ }^{4}$ En él se realizaba un diagnóstico sobre los problemas de seguridad y justicia en México. También se proponían soluciones que demandaban un cambio de paradigma en las políticas públicas de seguridad y justicia.

Según el estudio mencionado, los principios rectores de ese cambio implican las siguientes directivas: primacía del régimen constitucional de los derechos humanos; orientación hacia la seguridad humana; racionalización del uso de la fuerza; fortalecimiento del liderazgo civil; primacía de la prevención sobre el control; integralidad de la política para no fragmentar los esfuerzos del Estado; transversalidad para que todas las áreas involucradas se apropien de enfoques y criterios similares; coordinación y subsidiariedad; establecimiento de metodologías para afrontar los problemas de seguridad y justicia; eficacia y eficiencia en el empleo de los recursos aplicados a los fines; compromiso de todos los partidos políticos con las definiciones torales; máxima rendición de cuentas y transparencia; evaluación constante y responsable de las políticas, y atención prioritaria a quienes enfrentan los mayores riesgos y vulnerabilidad.

Los responsables de la política de seguridad y justicia en el país han desoído los diagnósticos y las propuestas de solución de análisis como el citado. Influidos y presionados por factores geopolíticos, aquéllos han abundado en los elementos represivos de la seguridad y la justicia, sin que al momento hayan tenido éxito alguno. El gobierno de los Estados Unidos desde 2002 incorporó de facto a México al Comando Norte. Posteriormente, Vicente Fox firmó la Alianza para la Seguridad y Prosperidad de América del Norte (ASPAN), que integró no sólo la política castrense a Norteamérica, sino también la social y la económica - aún más que la integración comercial derivada del NAFTA o TLCAN-. Durante el gobierno de Felipe Calderón, con el inició de la "guerra contra el narcotráfico", se potenció la integración en temas de seguridad con América del Norte mediante la Iniciativa Mérida, y con Peña Nieto se consolidó totalmente esa

4 "Elementos para la construcción de una política de Estado para la seguridad y justicia en democracia", México, UNAM-Instituto Iberoamericano de Derecho Constitucional, agosto de 2011. 
subordinación a los Estados Unidos, tanto con las reformas estructurales como con la concepción impuesta por el vecino del norte para que nuestro país forme parte plena de la seguridad nacional de los Estados Unidos.

A nivel externo, geopolítico, la centralización de poder en los presidentes mexicanos, que afecta a la vida federal, responde a la pretensión norteamericana para crear una zona hemisférica de seguridad, que mantenga las variables policiacas, militares y de inteligencia bajo un "control" superior, concentrado y manejable por encima de la base ciudadana. La estrategia hacia la integración total de América del Norte en los ámbitos de la energía, las telecomunicaciones, la educación, la cultura y la seguridad implica la realización previa de la integración en el orden interno de cada nación, que facilite la integración supranacional y la construcción y consolidación del poder imperial del vecino del norte. ${ }^{5}$

En este esquema geopolítico, de control supraestatal, tanto militar como policiaco, los principios y desarrollos jurídicos de soberanía nacional, federalismo y municipio libre son percibidos por el gobierno norteamericano como obstáculos contrahegemónicos que dificultan la materialización de sus objetivos de dominación. ${ }^{6}$

De esta suerte, la centralización jurídica y política de facultades, que es constantemente a favor del presidente de la República, y la integración interna de facultades y de recursos, en cada vez menos instancias constitucionales de poder nacional, significan una claudicación con los fines federales de la República. Los argumentos que se esgrimen para respaldar la Ley de Seguridad Interior son apelaciones al miedo social y a un pragmatismo sin contenido y antidemocrático, porque favorece a una voluntad centralista y autoritaria. Para los estados y municipios deben existir más, no menos, finanzas públicas y reformas constitucionales que amplíen, y no limiten, sus competencias.

En los dos últimos sexenios, la política de seguridad en el país consistió en el incremento acelerado del gasto militar; la guerra en contra de las drogas; la ocupación territorial, regional y estatal, sin procedimientos de

5 Rodríguez Rejas, María José, La norteamericanización de la seguridad en América Latina, México, Akal, 2017.

6 Petraeus, David H. et al., América del Norte. El momento de un nuevo enfoque, Nueva York, Council on Foreign Relations, 2014, Informe del Grupo de Trabajo Independiente, núm. 71, pp. 50-60; Ribando Seelke, Clare y Finklea, Kristin, "U.S.-Mexican Security Cooperation: The Mérida Initiative and Beyond", Washington, Congressional Research Service, 22 de julio de 2011, pp. 20-22. 
suspensión de garantías y sin respetar los procedimientos vigentes de intervención constitucional; la actuación ilimitada del ejército y de la marina en tareas de seguridad pública, entre otras acciones que prueban que la construcción de un Estado policiaco militar puede explicarse desde causas internas, como las violaciones al Estado de derecho en México. Sin embargo, desde nuestro punto de vista, las razones que originan la construcción de ese Estado militar son acuerdos externos y tienen que ver con la política de seguridad de los Estados Unidos y su determinación de integrarnos en lo que denominan "seguridad de Norteamérica" bajo su conducción. Nos intentan engañar señalando que nuestros enemigos, que son los de ellos, son el terrorismo y el crimen organizado. Nuestros adversarios han sido siempre los intereses geopolíticos de Norteamérica. ${ }^{7}$

Antes de explicar el interés geopolítico de los Estados Unidos en el tema de la seguridad es conveniente recurrir, para justificar nuestros argumentos, a marcos teóricos que nos explican lo qué es un Estado militar con tareas policiacas. En un estudio chileno, publicado por el Centro de Estudios Miguel Enríquez, se indica que un Estado militar-policial se caracteriza por:

1) Ser un Estado que mantiene un estricto control social, en donde se pueden suprimir algunas libertades civiles, además de legitimar a las fuerzas armadas para que éstas coadyuven con los fines del control.

2) Para que sea legítimo el control social, el Estado crea enemigos; éstos pueden ser el terrorismo, la lucha contra las drogas, el crimen organizado, etcétera.

3) A diferencia de los Estados democráticos, en el Estado militarizado, la seguridad no tiene fundamento en los derechos humanos ni en la voluntad democrática de las sociedades, sino en la noción de control social, la que es impuesta desde el gobierno.

4) El Estado militar puede conservar algunos elementos del Estado democrático, pero adopta algunos elementos de los Estados fascistas: leyes arbitrarias, excesivo control social y subordinación de los

7 Iniciativa del senador Bartlett presentada en el Senado de la República el 3 de enero de 2016 para modificar y adicionar la fracción XXIII del artículo 73 y que reforma la fracción VII del artículo 115 constitucional, que fue por mí redactada —www.senado.gob.mx Iniciativa_040216 - Las inquietudes anteriores ya estaban contenidas en una iniciativa presentada por mí previamente y que fue publicada en la Gaceta Parlamentaria el 11 de junio de 2012, en donde propongo modificar la fracción VI del artículo 89 constitucional. 
medios de comunicación para que éstos respalden la conveniencia del control.

5) El Estado militar es una expresión de la globalización neoliberal contemporánea, porque las empresas trasnacionales necesitan que los Estados, mediante la represión policiaca, protejan sus inversiones y sus intereses.

6) Es por ello que hay una incesante demanda por parte de los intereses trasnacionales de incrementar el poder de fuerza y de represión por parte del ejército.

7) La profesionalización y capacitación de militares y policías no se realiza desde una perspectiva de derechos humanos para proteger a las sociedades, sino se entiende que el uso de la fuerza es para reprimir a las sociedades si éstas demandan vías alternativas de convivencia.

8) En el Estado militar-policiaco se criminaliza la protesta y a los movimientos sociales; entre otras cosas, se asimila la protesta con el terrorismo o la delincuencia.

9) Se busca que los militares y los policías tengan un régimen jurídico de excepción para garantizarles altos niveles de impunidad por las conductas que los involucran. ${ }^{8}$

En una investigación nacional, realizada por Jaime A. Preciado Coronado y Ángel L. Florido Alejo, profesores de la Universidad de Guadalajara, y titulada "La militarización de las relaciones México-Estados Unidos; espacios ingobernables y ¿Estado fallido?”, se explica en clave geopolítica, con abundante información, el avance del ejército mexicano en tareas de seguridad que no les competen constitucionalmente. ¿Por qué interviene el ejército mexicano en tareas policiacas? Para controlar a la sociedad mexicana por mandato externo. Para ello, recurren a una doctrina de seguridad nacional en constante y acelerada evolución. Así, asumen intencionalmente confusiones conceptuales para mezclarlas entre ellas y mantener en constante incremento su fuerza e influencia política. Por ejemplo, se confunden e intercambian las categorías de seguridad pública, seguridad interior y seguridad nacional; se prioriza la inteligencia y la manipulación mediática con el terrorismo y la seguridad sobre otras consideraciones in-

8 "Estado policial. Una aproximación al concepto", Centro de Estudios Miguel Enríquez, 2005. 
ternas; se mezcla la incidencia del crimen organizado con los movimientos contestatarios; se promueve el miedo y el terror social a través de los medios de comunicación; se intenta que la sociedad vea con normalidad el intercambio de información y tareas entre las fuerzas militares nacionales y las norteamericanas; se justifica que el gobierno de los Estados Unidos tenga responsabilidad en la seguridad de su frontera sur; se abastece constantemente al ejército de armas y equipos; se promueven y materializan planes de seguridad de América del Norte, como la Iniciativa Mérida y el ASPAN, y ahora por medio de las Cumbres de las Américas; se justifica la integración de las fuerzas policiales nacionales y militares con proyectos de integración neopanamericanos; se debilita al Estado democrático y se exponen las deficiencias del Estado mexicano a través del uso de concepto de Estado fallido, el que fue creado por la inteligencia norteamericana, y se justifica, con la existencia en México de elementos de Estado fallido, la intervención de los Estados Unidos para concebir políticas de seguridad hegemónicas, de control y de integración, tanto en América del Norte como en América del Sur. ${ }^{9}$

El Estado militar-policiaco es, por tanto, una construcción teórica que explica la constante militarización en el mundo y en nuestra nación. Este tipo de Estado es una faceta de análisis del Estado neoliberal. Se ha incrementado inmensamente el poder de los ejércitos y las policías para tutelar el modelo económico del Estado neoliberal. Las grandes potencias, como los Estados Unidos, se asumen responsables del proceso para mantener condiciones aceptables de reproducción del capitalismo contemporáneo en beneficio de las grandes empresas trasnacionales, y para apuntalar sus áreas de influencia en la lucha por la hegemonía mundial. Por eso, países como México han recibido el impacto de esta concepción geopolítica — sobre todo porque constituimos la frontera sur de los Estados Unidos- y, sin importar nuestras estructuras políticas formales o las necesidades domésticas, el modelo del Estado militar-policiaco se impone y los gobiernos cómplices lo reciben con agrado y sin oponerse para no agraviar a la potencia. Sin embargo, es tan nociva esta nueva estructuración del Estado que en los propios Estados Unidos la violencia militar y policiaca ha provocado

9 Preciado Coronado, Jaime A. y Florido Alejo, Ángel L., "La militarización de las relaciones México-Estados Unidos; espacios ingobernables y ¿Estado fallido?”, US National Security Concerns in Latin America and the Caribbean, Nueva York, Palgrave Macmillan, 2014, pp. 61-79. 
en muchas ciudades reacciones contrarias y de oposición por parte de la sociedad civil. ${ }^{10}$

Sustentamos la existencia del Estado militar y policiaco, así como el carácter geopolítico y externo de su imposición, con estudios y declaraciones emitidas por autoridades y académicos de los Estados Unidos, con las propias declaraciones de las autoridades nacionales y, desde luego con la observancia de los hechos con una visión amplia, informada, geopolítica y no deliberadamente parroquial.

En el documento "North América Time for a New Focus", elaborado por David H. Petraeus, Robert B. Zoellick y Shannon K. O’Neil, se señala: "Norteamérica ha progresado desde las guerras del Siglo XIX a la hoy pacífica cooperación en contra de amenazas comunes. Esta relación de seguridad es esencial para el futuro de Norteamérica. Tener inseguridad en cualquiera de estos tres países elimina la habilidad para contribuir y beneficiarse de una región integrada". ${ }^{11}$

La Fuerza de Cooperación Especial recomienda trabajar hacia una meta a largo plazo de una nueva estrategia de seguridad unificada para Norteamérica. Dicho proceso podría empezar por expandir los programas de seguridad bilaterales para incluir a México. Los programas Estados Unidos-Canadá podrían ser incorporados a la iniciativa "México-Estados Unidos manejo fronterizo del Siglo XXI", estos esfuerzos podrían incluir el considerar los riesgos de seguridad más allá de las fronteras y desarrollar un sistema conjunto de análisis de riesgos y amenazas para la "zona" Norteamericana. México podría también participar en el programa conjunto de EEUU-Canadá "Shiprider", el cual está formado por grupos de múltiples agencias de seguridad que se enfocan en la actividad criminal transfronteriza. Estos pasos requerirían que México dedicara personal de las fuerzas de seguridad hacia la seguridad de sus fronteras Sur y Norte. Para alcanzar una estrategia de seguridad unificada, los tres países deberían desarrollar la confianza para compartir la información de manera segura entre agentes aduanales, agentes fronterizos, fuerzas de seguridad, oficiales de justicia y personal militar. $^{12}$

10 Chamseddine, Roqayah, "La militarización de las agencias de policía. Desde Ferguson hasta el Medio Oriente", trad. de Colectivo Todo Poder al Pueblo, Centro de Medios Libres, 26 de agosto de 2014.

11 Petraeus, David H. et al., "North America Time for a New Focus", Independent Task Force Report, núm. 71, 2014, p. 24.

12 Ibidem, p. 25. 
Parte fundamental de la justificación de la Iniciativa Mérida, según los documentos oficiales de los Estados Unidos, es que la corrupción prevalece en las policías mexicanas, y demandan para erradicarla un papel mayor de los militares, además, y es obvio, de la asistencia militar a México por parte de los Estados Unidos. Lo dicen así:

El establecimiento de los comandos unificados de policías estatales que potencialmente podrían absorber a las fuerzas policiacas municipales, ha sido debatido en México por años. El Congreso mexicano falló en aprobar una propuesta de reforma constitucional presentada por el gobierno de Calderón para establecer Comandos Unificados de Policía Estatal. Sin embargo, el presidente Peña Nieto está ayudando a los estados a moverse en esa dirección y ha introducido su propia propuesta de reforma constitucional sobre este tema. El resultado de los esfuerzos para una reforma policiaca militar podría tener implicaciones en las iniciativas de Estados Unidos de expandir la asistencia del plan Mérida para cubrir a fuerzas estatales y municipales, ya que el gobierno mexicano determina cómo se organiza y canaliza esa asistencia. Los recursos del fondo Mérida han mantenido academias estatales y cursos de entrenamiento para policías estatales y locales en seguridad de los oficiales, el aseguramiento y preservación de las escenas del crimen, técnicas de investigación y la recopilación de inteligencia. ${ }^{13}$

En el terreno de la seguridad, la compenetración entre los tres países es total. ${ }^{14}$ Por ejemplo, en materia energética, los norteamericanos han señalado las deficiencias de inseguridad de la infraestructura nacional en esta materia y han exigido una permanente colaboración entre las tres naciones para remediarla. Duncan Wood señala que se deben hacer esfuerzos de los tres gobiernos de América del Norte para prevenir ataques a las infraestructuras energéticas que se consideren críticas $\mathrm{y}$, en ese sentido, las agencias de inteligencia de los tres países deben trabajar de la mano con los ministerios de energía correspondientes. El Departamento de Homeland Security, la Seguridad Pública de Canadá y el Cisen deberán crear un panel de expertos trilaterales que mantengan relaciones de trabajo con los sectores públicos y privados interesados para desarrollar un marco de largo plazo,

13 Ribando Seelke, Clare y Finklea, Kristin, "U.S.-Mexican Security Cooperation: The Mérida Initiative and Beyond", Washington, Congressional Research Service, 7 de mayo de 2015, p. 12.

14 Rodríguez Rejas, María José, La norteamericanización de la seguridad en América Latina, México, Akal, 2017, pp. 271 y ss. 
que sirva para planear y establecer objetivos, calendarios y comités, a fin de prevenir y enfrentar ataques — con capacidades de actuación en automático ante cualquier riesgo - en esa infraestructura, que se considera fundamental para la preservación de la seguridad energética de América del Norte. ${ }^{15}$

No es, por tanto, casual que el Congreso mexicano se haya dedicado durante la administración de Peña Nieto a aprobar reformas coincidentes con las exigencias de seguridad militar y de inversiones de los Estados Unidos. Ejemplo de ello es el transitorio octavo de la reforma constitucional energética publicada en el Diario Oficial de la Federación el 20 de diciembre de 2013, el cual estipula lo siguiente:

Derivado de su carácter estratégico, las actividades de exploración y extracción del petróleo y de los demás hidrocarburos, así como el servicio público de transmisión y distribución de energía eléctrica, a que se refiere el presente Decreto se consideran de interés social y orden público, por lo que tendrán preferencia sobre cualquier otra que implique el aprovechamiento de la superficie y del subsuelo de los terrenos afectos a aquéllas. La ley preverá los términos y las condiciones generales de la contraprestación que se deberá cubrir por la ocupación o afectación superficial o, en su caso, la indemnización respectiva. Los títulos de concesiones mineras que se encuentren vigentes a la entrada en vigor de este Decreto y aquellos que se otorguen con posterioridad, no conferirán derechos para la exploración y extracción del petróleo y los demás hidrocarburos sólidos, líquidos o gaseosos, sin perjuicio de los derechos previstos en sus propias concesiones. Los concesionarios deberán permitir la realización de estas actividades. La ley preverá, cuando ello fuere técnicamente posible, mecanismos para facilitar la coexistencia de las actividades mencionadas en el presente transitorio con otras que realicen el Estado o los particulares.

El transitorio octavo de la reforma constitucional energética de 2013 establece que el sector energético tiene prevalencia sobre cualquier otra actividad. ${ }^{16}$ Ello permitirá, mediante el empleo de la fuerza pública nacional y externa - a favor de las trasnacionales - expropiar y disponer de la propiedad privada, pública y social por encima de cualquier otro derecho. La norma transitoria será fuente de conflictos sociales por la propiedad y

15 Wood, Duncan, "Integrating North America's Energy Markets: A Call for Action", Wilson Center Institute, diciembre de 2014, p. 14.

16 Cárdenas Gracia, Jaime, Crítica a la reforma constitucional energética, México, UNAM, 2014. 
la posesión de la tierra. Las empresas trasnacionales del petróleo y de la electricidad, como ahora ocurre con las empresas mineras, argumentarán a su favor el carácter preferente de las actividades energéticas. Los ejidos, comunidades y pueblos indígenas sostendrán como preferentes sus derechos sobre la tierra. Sin embargo, con este artículo octavo transitorio de la reforma energética, el régimen de propiedad de la tierra cambia totalmente en el derecho mexicano. La propiedad privada, social o pública estará subordinada a las actividades preferentes de la industria energética, y las expropiaciones u "ocupaciones temporales" sobre la propiedad privada, pública o social podrán realizarse para satisfacer los intereses privados de las empresas trasnacionales del petróleo y de la electricidad. La reforma constitucional en esta norma transitoria pone a disposición de las empresas trasnacionales el territorio nacional y tendrán, además, de su lado a la fuerza policiaco-militar de México y de los Estados Unidos.

Otro ejemplo fueron las reformas a ley para revenir y sancionar los delitos cometidos en materia de hidrocarburos publicadas en el Diario Oficial de la Federación el 12 de enero de 2016. La reforma también adicionó la fracción XXIII, derogó el inciso 19 y reformó el inciso 25 de la fracción I, todos del artículo 194 del Código Federal de Procedimientos Penales, además de reformar el artículo 254 ter, adicionar la fracción VI y derogar el inciso $j$ de la fracción I del artículo 253, las fracciones VII y VIII del artículo 254, y el artículo 368 quáter del Código Penal Federal. Igualmente, se reformó la fracción I y se adicionó la fracción VIII al artículo 2o. de la Ley Federal contra la Delincuencia Organizada.

Tales cambios establecieron en México un régimen especial de carácter penal en materia de hidrocarburos, el que es propio de lo que la doctrina denomina "derecho penal del enemigo" y que es anticonstitucional; es decir, un sistema que atribuye sanciones penales en función de la peligrosidad de los futuros autores de las conductas y no de las conductas mismas. La reforma criminaliza la protesta social de indígenas, ejidatarios, pequeños propietarios y de otros mexicanos, con las categorías penales de terrorismo y sabotaje, que se incluyen en ella. Evidentemente, se trata de una reforma legal para proteger los intereses de los inversionistas extranjeros en México en el ámbito de la energía, lo que coincide con los intereses norteamericanos reclamados pública e insistentemente cuando los sectores empresariales y extranjeros afirman que "sin mayor seguridad no habrá inversión extranjera". 
En el mismo sentido, se aprobaron las reformas a la Ley Federal de Armas de Fuego y Explosivos — publicadas en el Diario Oficial de la Federación el 12 de noviembre de 2015-, las que indebidamente e inconstitucionalmente se fundamentaron en el Acuerdo entre el Gobierno de los Estados Unidos Mexicanos y el Gobierno de los Estados Unidos sobre Asistencia Mutua entre sus Administraciones de Aduanas, del 9 de diciembre de 2013. Las normas legales en México sólo pueden tener por fundamento jurídico para su creación o reforma una norma de mayor jerarquía y no una norma de menor jerarquía como es en el presente caso. Asimismo, el citado Acuerdo es interinstitucional, porque no fue aprobado por el Senado, en contravención del artículo 76, fracción I, de la Constitución. No puede haber reciprocidad del gobierno mexicano con la brutal asimetría con los Estados Unidos. ${ }^{17}$

La anterior reforma violó el principio de legalidad y certeza, pues es ambigua, vaga e indeterminada. Por ejemplo:

1) No define cuántos permisos individuales o colectivos se otorgarán a los agentes extranjeros armados en nuestro país.

2) No precisa el número máximo de agentes armados extranjeros que podrán existir en nuestro país.

3) No precisa cuántos agentes extranjeros habrá por cada una de las 94 estaciones migratorias en México y por cada una de las decenas de recintos aduaneros del país.

4) No precisa la cantidad de armamento y equipo que estará a disposición de cada agente extranjero.

5) No precisa las relaciones de mando y de coordinación entre los agentes migratorios y aduanales extranjeros con los agentes aduanales y migratorios nacionales.

6) No precisa si en las rutas, caminos o transporte los agentes extranjeros también portarán armas.

7) No define qué se entiende por el término "reciento o local migratorio o aduanal".

17 Iniciativa del senador Bartlett presentada en el Senado de la República el 3 de enero de 2016 para modificar y adicionar la fracción XXIII del artículo 73 y que reforma la fracción VII del artículo 115 constitucional, que fue por mí redactada —www.senado. gob.mx Iniciativa_040216-. Las inquietudes anteriores ya estaban contenidas en una iniciativa presentada por mí previamente y que fue publicada en la Gaceta Parlamentaria el 11 de junio de 2012, en donde propongo modificar la fracción VI del artículo 89 constitucional. 
8) No define el número máximo de prórrogas que se otorgarán por el gobierno mexicano a los permisos individuales o colectivos.

9) No define cuál es el juez penal competente en caso de que un agente extranjero cometa un delito en territorio nacional.

10) No se establece cuál es el régimen jurídico al que estarán sujetos los agentes extranjeros en su relación con la población mexicana y en relación con las autoridades nacionales, lo que hace suponer que los sistemas migratorio y aduanal mexicanos estarán sometidos al control y a la administración del gobierno de los Estados Unidos y no de los mexicanos.

Consideramos que nuestros servicios de migración y aduanas estarán bajo la autoridad de la Homeland Security del gobierno norteamericano, que es el organismo establecido desde el gobierno de George W. Bush para combatir, sin ninguna limitación, el terrorismo, violando derechos humanos.

El principio de reciprocidad del que habla la reforma de la Ley Federal de Armas de Fuego y Explosivos debe estar previsto en un tratado para ser válido, porque compromete la soberanía de las naciones involucradas. Por tanto, no puede estar contemplado en un acuerdo interinstitucional que no es aprobado por el Senado de la República, ya que este tipo de acuerdos carecen de la legitimidad constitucional derivada de la representación política nacional de cada estado.

Podemos decir que los documentos citados y las reformas aprobadas en México en los últimos años son pasos en el proceso de integración de nuestro país a la seguridad norteamericana - léase de Estados Unidos-, lo que conlleva la pérdida acelerada y permanente de la soberanía nacional.

Como dijimos desde el principio del ensayo, la política de seguridad de nuestro país se dirige a la integración militar y de seguridad de México a la órbita de las decisiones norteamericanas. La soberanía de una nación tiene que ver fundamentalmente con el control de su fuerza pública y militar, y México pierde a pasos acelerados el control pleno sobre sus fuerzas de seguridad a favor de la integración de América del Norte y de los Estados Unidos para el provecho y beneficio de ese país.

Las declaraciones de las autoridades mexicanas coinciden con lo que aquí señalamos: los pronunciamientos del secretario de Gobernación ${ }^{18}$ y de

18 Mensaje de Miguel Ángel Osorio Chong del 28 de enero de 2016 durante la inauguración de los trabajos de la VIII reunión plenaria de los senadores del PRI y del PVEM a la LXIII Legislatura. 
los gobernadores integrantes de la Conago argumentan a favor del control y de supervisión de las policías por las fuerzas armadas. La finalidad de una ley de seguridad interior que propone el gobierno federal no es para garantizar los derechos humanos de los habitantes del país, sino para establecer de jure el "control" sobre las fuerzas de seguridad pública por parte de las fuerzas armadas, y éstas, a su vez, someterlas al Comando Norte del ejército norteamericano.

En esta parte contextual del trabajo, recupero un fragmento del artículo escrito por Carlos Fazio, publicado en La Jornada y titulado "Geopolítica y despojo". Dice Fazio:

Hace veinte años, la mañana del 23 de octubre de 1995, el Jefe del Pentágono, William Perry, dijo ante la plana mayor del Ejército Mexicano que entre Estados Unidos y México existían fuertes lazos políticos y económicos, pero que faltaba un "tercer vínculo", el militar. A partir de entonces, promovida por Washington, la sana distancia entre las fuerzas armadas de ambos países comenzó a acortarse... la finalidad de los gobiernos mexicanos bajo la supervisión de los Estados Unidos, ha sido la de desordenar, destruir, reconstruir, reordenar, todas nuestras estructuras constitucionales, legales, políticas, económicas y sociales, para favorecer al gran capital trasnacional por encima de los derechos humanos de las poblaciones y, en contra de los derechos territoriales de la nación mexicana a sus recursos naturales. ${ }^{19}$

\section{ALGUNAS INICIATIVAS DE LEY PRESENTADAS} EN MATERIA DE SEGURIDAD INTERIOR

A partir de los atentados terroristas en Nueva York de 2001 y la expedición de la Patriot Act, el gobierno norteamericano modificó su política de seguridad para América Latina. A los norteamericanos les interesa, mediante vías diferentes a las que usaron en el pasado, proteger sus inversiones e intereses en países como el nuestro. Ellos han decidido, para su propio beneficio, tener resguardados en México los puertos, los aeropuertos y los sistemas que contienen megadatos, pero también las instalaciones energéticas, los recursos mineros, los recursos hídricos, entre otros. Es incorrecto suponer que una ley de seguridad interior sólo trata de enfrentar a los cárteles del crimen organizado y de seguir promoviendo la guerra contra las

19 Fazio, Carlos, "Geopolítica y despojo”, La Jornada, 26 de octubre de 2015. 
drogas, iniciada en el gobierno de Calderón. La pretensión para aprobar una ley de seguridad interior es subordinar la seguridad nacional y los recursos de México a los designios geopolíticos de los Estados Unidos, como siempre ha sido, pero ahora con otros medios e instrumentos, que consisten en respaldar y estimular gobiernos neoliberales de diseño policiaco-militar.

Se han presentado en el Congreso de la Unión distintas iniciativas que están a favor de una ley de seguridad interior. Entre ellas se encuentran las siguientes:

\section{La iniciativa del senador Roberto Gil Zuarth ${ }^{20}$}

Esta iniciativa estima aumentar las competencias de las fuerzas armadas en materia de seguridad, y establece, como quiere hacer creer el gobierno norteamericano, que los enemigos son el crimen organizado y el terrorismo, y no las amenazas geopolíticas de los Estados Unidos. La iniciativa carece de planteamientos en este ámbito y tampoco cuestiona los intereses de los Estados Unidos en el proceso de militarización nacional.

Nuestras críticas a ella son las siguientes:

1) El orden constitucional, los derechos humanos y la gobernabilidad democrática no pueden estar salvaguardados en última instancia por las fuerzas armadas. El control constitucional, de acuerdo con la reforma constitucional de los derechos humanos publicada el 10 de junio de 2011, corresponde a todas las autoridades y, desde nuestro punto de vista, también a los ciudadanos. El garante final de la Constitución es el Poder Judicial de la Federación, en específico la Suprema Corte de Justicia de la Nación. El artículo 20. de la propuesta del senador Gil Zuarth constituye una aberración jurídica de carácter constitucional y democrático.

2) La iniciativa de ley del senador Gil propone en el artículo 4o., fracción VII, que las fuerzas armadas realicen cateos, arraigos e intervenciones de comunicaciones con autorización de los jueces de control. Las atribuciones anteriores corresponden a la policía y al Ministerio Público con autorización judicial, y no deben ser usurpadas por las fuerzas armadas. Esta norma debe interpretarse sistemáticamente en relación con toda su iniciativa, en particular,

20 Iniciativa del13 de septiembre de 2016. 
con las fracciones III, IV, V, VI, VIII, XII y XIII del artículo 29 de la iniciativa, que facultan a las fuerzas armadas, en los supuestos del procedimiento de afectación interior, a practicar cateos, arraigos, intervenciones, etcétera, en auxilio del Ministerio Público o en coadyuvancia con él.

3) El artículo 29 de la iniciativa del senador Gil Zuarth, en relación con el artículo 4o., fracción VII, y otras normas de su propuesta, prevé intervenciones de las fuerzas armadas en cateos y detenciones en las hipótesis de afectación interior. Según la iniciativa, las fuerzas armadas se suman a esas tareas, ya sea con autorización del juez de control o en auxilio o coadyuvancia con el Ministerio Público.

4) La fracción $X$ del artículo 4o. de la iniciativa establece que el uso legítimo de la fuerza por parte de las fuerzas armadas se puede emplear para controlar, repeler o neutralizar actos de resistencia no agresiva, lo que equivale a criminalizar cualquier manifestación y acto de protesta social no violento.

5) Los conceptos que integran la seguridad interior, previstos en el artículo 6o. de la iniciativa, entrañan la imposibilidad para el ejercicio de diversos derechos humanos, como los de manifestación, expresión, reunión, protesta y resistencia civil pacífica. Con esta ley se quiere una ciudadanía inmovilizada e incapaz de rebelarse en contra de la opresión, aun por las vías pacíficas. Desde nuestra posición, los conceptos jurídicos que integran la seguridad interior implican limitaciones a los derechos humanos, porque la interpretación de esas hipótesis corresponderá a las autoridades aplicadoras, que son autoridades de seguridad y de carácter militar. Una protesta ciudadana, una manifestación, una reunión o hasta la expresión ciudadana puede ser entendida por esas autoridades como un acto tendente a infiltrar o capturar las instituciones de seguridad. También las acciones tendentes a impedir la administración o ejecución de programas federales —artículo 6o., fracción IIIpueden colisionar con los derechos a la protesta y manifestación ciudadana.

6) El segundo párrafo del artículo 7o. excluye de la materia la aplicación de la Ley Federal de Procedimiento Administrativo y, con ello, el principio de legalidad. ¿Por qué esa ley no sirve para funda- 
mentar decisiones en materia de seguridad interior cuando se aplica en todos los ámbitos de la administración pública? Mi respuesta es que se hace o se pretende hacer así para favorecer la discrecionalidad y hasta la arbitrariedad de las fuerzas armadas.

7) El Comité de Seguridad Interior — artículo 8o. de la iniciativamezcla autoridades civiles con militares y autoridades ejecutivas con legislativas. El propósito es impedir el control legislativo y jurisdiccional de los actos y resoluciones de ese Comité.

8) El último párrafo del artículo 8o. de la iniciativa del senador Gil establece la confidencialidad y reserva de todas las actuaciones del Comité de Seguridad Interior.

9) El único mecanismo de control legislativo serán los informes del secretario de Gobernación - artículo 11-a la Comisión Bicameral del Congreso. Esta Comisión no sesiona ni delibera en público ni informa al pleno de las cámaras ni a la ciudadanía; es decir, la Comisión Bicameral es para simular que existe control legislativo cuando no existe ninguno. Los invitados de la Comisión Bicameral a las reuniones del Comité de Seguridad Interior fungirán como invitados de piedra.

10) El artículo 22 de la iniciativa del senador Gil faculta a las fuerzas armadas a establecer retenes por doquier y a inspeccionar a las personas y sus bienes sin órdenes judiciales.

11) El artículo 22, fracción II, inciso $b$, de la iniciativa alude a una imposibilidad material: "el empleo de fuerza no letal" por parte de las fuerzas armadas.

12) Las fuerzas armadas, de acuerdo con el artículo 22, fracción II, inciso $c$, pueden actuar para contrarrestar la resistencia no agresiva, para impedir la comisión inminente de delitos, para controlar a las personas que se resistan a una detención.

13) Las declaratorias de seguridad interior no siguen el procedimiento de suspensión de garantías del artículo 29 constitucional. Se publican en el Diario Oficial de la Federación y se notifican a la Comisión Bicameral y a la Comisión Nacional de los Derechos Humanos. Es decir, se suspenden derechos humanos y garantías sin el procedimiento correspondiente del artículo 29 constitucional.

14) La declaratoria de afectación a la seguridad interior puede ser hasta por 180 días y puede prorrogarse por un periodo igual - artículo 24 , lo que implica que podría emitirse después de esos plazos 
y así sucesivamente — artículo 24- La suspensión de garantías sería indefinida, sin límite, es decir, la legalización de un régimen autoritario.

15) El artículo 28 de la iniciativa del senador Gil Zuarth mantiene el fuero militar más allá de lo previsto en el artículo 13 de la Constitución.

16) En el artículo 29 se le conceden a las fuerzas armadas competencias de policía y de Ministerio Público.

17) En el artículo 32 de la iniciativa del senador Gil se le otorga competencia a las fuerzas armadas para intervenir en las comunicaciones privadas, con autorización de jueces de control; pero los datos e información se resguardan bajo la responsabilidad de las fuerzas armadas. Las intervenciones a las comunicaciones privadas se entienden como información reservada y pueden utilizarse como prueba en los procedimientos penales cuando las fuerzas armadas actúan en auxilio de la policía o del Ministerio Público.

18) El artículo 40 faculta a las fuerzas armadas a llevar a cabo el espionaje de archivos y equipo informático con autorización judicial.

19) El artículo 41 faculta a las fuerzas armadas a realizar la geolocalización de personas con autorización judicial.

20) Las facultades de control legislativo de la Comisión Bicameral son limitadas e insuficientes para reducir los excesos y arbitrariedad de las fuerzas armadas - artículo 43-. Los miembros de la Comisión Bicameral deben guardar la secrecía sobre sus actuaciones.

21) Todas las autoridades estatales y municipales, al emitirse las declaratorias de seguridad interior, quedan subordinadas a las fuerzas armadas. Se trata de medidas centralistas y militaristas.

22) No existe capítulo de responsabilidades y sanciones por ejercicio indebido de las competencias conferidas a las autoridades competentes en materia de seguridad interior.

\section{Iniciativa de los diputados César Octavio Camacho Quiroz y Martha Sofía Tamayo Morales ${ }^{21}$}

De manera más brutal que la iniciativa de Gil Zuarth, se faculta a las fuerzas armadas a colocarse por encima de las policías en las tareas de seguridad

21 Iniciativa del 27 de octubre de 2016. 
pública. Se faculta a las fuerzas armadas, sin control alguno, a realizar acciones en contra de la población y sus derechos humanos. Se trata de una iniciativa totalmente contraria a la Constitución, a la democracia y a los derechos humanos. Principalmente, dicha iniciativa oculta la intervención o la influencia norteamericana en la exigencia de una ley de seguridad interior.

Criticamos esta iniciativa por las siguientes razones:

1) La iniciativa alude en su artículo 3o. a la Declaratoria de Protección a la Seguridad Interior. Ésta se realiza sin cumplir el procedimiento de suspensión de garantías del artículo 29 constitucional.

2) En la iniciativa se prevén acciones de orden interno que implican actividades de seguridad pública, sin autorización judicial. Por ejemplo, se legalizan los retenes y la revisión de las personas y bienes privados por las fuerzas armadas.

3) La definición de seguridad interior se otorga a las fuerzas armadas la calidad de garantes del Estado, de sus instituciones, del desarrollo nacional, del mantenimiento del Estado de derecho y la democracia, lo que invierte el principio de primacía de la autoridad civil y de los ciudadanos a favor de las fuerzas armadas. Se trata de una definición militarista contraria a los fundamentos del Estado de derecho - fracción VI del artículo 30.-

4) La iniciativa del PRI ni siquiera alude al control de la Comisión Bicameral ni al control jurisdiccional de las decisiones que adopten las autoridades competentes - artículo 4o.-.

5) Se establece que en la materia no será aplicable la Ley Federal de Procedimiento Administrativo, como lo cual se favorece la violación de los principios del debido proceso - artículo 5o., párrafo segundo-.

6) La información derivada de los procedimientos de la Ley son confidenciales para evitar cualquier tipo de escrutinio público y control social.

7) Los acuerdos de la declaratoria de seguridad interior se aprueban por el presidente de la República, previa consideración del Consejo de Seguridad Nacional, que está integrado por los titulares de las fuerzas armadas y mayoritariamente, por funcionarios dependientes del propio titular del Ejecutivo - artículo 11-.

8) En la iniciativa de los diputados se establece que la Declaratoria de Protección a la Seguridad Interior podrá prorrogarse indefinidamente - artículo 15-. 
9) Todas las autoridades estatales y municipales, al emitirse las declaratorias de seguridad interior, quedan subordinadas a las fuerzas armadas. Se trata de medidas centralistas y militaristas.

10) Las acciones de orden interno y de seguridad interior están orientadas por labores de espionaje sin ningún tipo de control legislativo o judicial.

11) El único control que prevé la iniciativa consiste en que el secretario de Gobernación informe al presidente de la República y a la Comisión Bicameral.

12) Evidentemente, no existe capítulo de responsabilidades ni de sanciones en toda la ley por el ejercicio indebido de las competencias conferidas a las autoridades.

\section{La iniciativa del diputado Manuel de Jesús Espino Barrientos ${ }^{22}$}

La iniciativa busca superar la inconstitucionalidad en la aprobación de una ley de seguridad interior, porque el Congreso de la Unión carece de facultades para expedir una ley de esa naturaleza — sólo tiene facultades para aprobar leyes en materia de seguridad nacional—. Sin embargo, las finalidades son las mismas que las que presentan las iniciativas anteriores e implican subordinación a las decisiones geopolíticas del gobierno norteamericano.

Nuestras críticas son las siguientes:

1) La iniciativa propone modificar la Ley de Seguridad Nacional.

2) Dicha iniciativa incluye a la seguridad interior dentro de la seguridad nacional.

3) Esta iniciativa dota de más competencias al Consejo de Seguridad Nacional y a las autoridades que se desprenden de él.

4) El Consejo de Seguridad Nacional se transforma en una instancia centralista que subordina a las autoridades estatales y municipales.

5) Se autoriza el empleo de las fuerzas armadas en el amplio concepto de seguridad nacional que enuncia la ley. Es decir, pueden las fuerzas armadas ocuparse de cualquier tarea de seguridad nacional que se define en los artículos 3o., 4o. y 5o., y cuya reforma se propone en la iniciativa a la ley de seguridad nacional.

22 Iniciativa del 5 de enero de 2017. 
6) Esta iniciativa, que aparentemente no tiene el nivel de militarismo de las anteriores, es mucho más perniciosa, porque deja abiertas las puertas de cualquier tema de la agenda nacional a la competencia de las fuerzas armadas.

7) Su riesgo es que las competencias que en un Estado de derecho deben realizar las autoridades civiles y los ciudadanos son conferidas a las fuerzas armadas. La iniciativa propende a la militarización del país.

\section{Inconstitucionalidad de las iniciativas presentadas}

Las anteriores iniciativas, entre otras presentadas, son inconstitucionales por las siguientes razones:

1) Se viola el artículo 73 constitucional. El artículo 73 de la Constitución no establece la competencia expresa del Congreso de la Unión para expedir una ley de seguridad interior. La seguridad interior en México, desde una interpretación conforme, está vinculada a la suspensión de garantías —artículo 29 de la Constitución- y a la intervención federal prevista en el primer párrafo del artículo 119 de la Constitución, así como a los mecanismos de desaparición de poderes y resolución de conflictos políticos entre las entidades federativas - artículo 76, fracciones IV, V y VI, de la Constitución- L La seguridad interior no es seguridad pública ni seguridad nacional, sino una categoría diversa.

2) Se infringe también el artículo 73 constitucional, porque el Congreso de la Unión no cuenta con facultades para emitir una ley de coordinación para distribuir competencias en materia de seguridad interior. La jurisprudencia de la Suprema Corte hasta el momento ha sido constante y ha estimado que sólo cabe una ley que asigne competencias entre los tres órdenes de gobierno cuando: $a$ ) de manera expresa se ha modificado el artículo 73 de la Constitución para habilitar a las cámaras a aprobar una ley de esas características, y $b$ ) cuando la Constitución encomienda expresamente la competencia al Estado mexicano en su conjunto. En el caso concreto, ni se ha reformado el artículo 73 ni otro precepto de la Constitución para otorgar facultades para legislar sobre esa coordinación, y tampoco la Constitución, en su artículo 89, fracción VI, determina 
que la materia de seguridad interior corresponde al Estado en su conjunto. ${ }^{23}$

3) Se violan los artículos 39, 40, 41 y 49 de la Constitución. Nuestra Constitución indica que la soberanía reside en el pueblo y que el Estado mexicano es una república, representativa, democrática, federal y laica. No puede, por tanto, establecerse un régimen militar de excepción como forma de gobierno o de Estado sin que se cumplan los extremos de los artículos 29 y 119; 76, fracciones IV, $\mathrm{V}$ y VI, y constitucionales. ${ }^{24} \mathrm{El}$ militarismo bajo la égida de uno de los poderes - el Ejecutivo - es coincidente con el autoritarismo, pero no con la democracia ni con la república, además de infringirse el principio de división de poderes.

4) Se viola el artículo 29 de la Constitución. Las condiciones jurídicas y políticas de excepción en el país o en alguna parte de su territorio, constitucionalmente, sólo pueden darse a través del procedimiento de suspensión de derechos y garantías. No puede establecerse un régimen de excepción, transitorio o permanente, para emplear las fuerzas armadas y preservar el orden, o enfrentar riesgos y amenazas internos, bajo procedimientos legales que no se fundamenten en la Constitución, como es el objetivo de la Ley de Seguridad Interior.

5) Se viola el artículo 119, primer párrafo, de la Constitución. La intervención federal que contempla ese precepto es a petición de las legislaturas o por el Ejecutivo de cada entidad, en caso de que aquéllas no estuvieran reunidas. Jamás la intervención federal del artículo 119 constitucional le da facultades al titular del Poder Ejecutivo Federal para iniciar el procedimiento que prevé esa norma.

6) Se viola el artículo 129 de la Constitución. La norma indica que en tiempo de paz el lugar de las fuerzas armadas son los cuarteles. Por lo tanto, las fuerzas armadas no pueden ocuparse de la seguridad interior, salvo supuestos constitucionales específicos y excepcionales (artículos 29; 76, fracciones IV, V y VI, y 119 de la Constitución). Su espacio es el de los cuarteles y fortalezas militares, y su función, la disciplina estrictamente militar.

23 Cano, Luis Miguel, Seguridad interior, México, Litiga, 2018, pp. 64-67.

24 Agamben, Giorgio, Estado de excepción. Homo sacer, II, 1, Buenos Aires, Adriana Hidalgo Editora, 2005. 
7) Se viola el artículo 21 de la Constitución. Aunque se argumenta que las acciones de seguridad interior no tendrán la condición de seguridad pública, lo cierto es que la actuación de las fuerzas armadas no tendrá otro propósito que ése: combatir el crimen organizado. El artículo 21 constitucional, con claridad meridiana, estatuye que la seguridad pública es una competencia de carácter civil.

8) Se violan los artículos 1o., 10, 11, 14 y 16 de la Constitución. Las iniciativas proponen vulnerar los derechos humanos a manos de autoridades militares; el bloque completo de constitucionalidad y convencionalidad; los derechos de reunión, manifestación y tránsito, que se verán restringidos permanentemente con las declaratorias de "protección" a la seguridad interior y con las acciones permanentes para prevenir los riesgos, y los derechos vinculados al debido proceso, que prohíben que las personas sean molestadas en sus propiedades, posesiones o papeles, a menos que sea a través de mandamientos de las autoridades competentes.

9) Se viola el artículo 89, fracción VI, de la Constitución. Una correcta interpretación del artículo 89, fracción VI, que dota al Ejecutivo de competencias para emplear las fuerzas armadas para la seguridad interior, sólo es compatible con lo dispuesto en los artículos 29; 76, fracciones IV, V y VI, y 119 de la Constitución. No se puede interpretar de otra forma el artículo 89, fracción VI, porque ello equivaldría a vulnerar el principio de división de poderes, el principio de control de los actos del Ejecutivo, la soberanía de los estados y el principio de municipio libre — unas fuerzas armadas en el territorio nacional que obvian y menosprecian los controles constitucionales de los poderes Legislativo y Judicial, y la soberanía estatal y municipal- Sólo excepcionalmente y en el marco de los artículos 29; 76, fracciones IV, V y VI, y 119 constitucionales sería permisible el empleo de las fuerzas armadas para la seguridad interior. El argumento analógico debe ser empleado aquí: si para declarar la guerra el presidente debe contar con la autorización del Congreso — artículos 73, fracción XII, y 89, fracción VIII-, también para emplear las fuerzas armadas con fines de seguridad interior, requiere del concurso de los otros poderes de la Unión, atendiendo a lo dispuesto en los artículos 21; 29; 49; 76, fracciones IV, V y VI; 119, y 129 de la Constitución. 
El recorrido histórico constitucional del concepto de seguridad interior inicia como facultad del Supremo Poder Ejecutivo en la fracción VI del artículo 16 del Acta Constitutiva de la Federación, del 31 de enero de 1824. Sus antecedentes hacían referencia al "orden interior" como una facultad del emperador en el artículo 30 del Reglamento Provisional Político del Imperio Mexicano, 18 de diciembre de 1822, y a la "tranquilidad interior" como una facultad del Supremo Gobierno en el artículo 160 del Decreto Constitucional para la Libertad de la América Mexicana, 22 de octubre de 1814, mismo en el que por primera vez se alude también a la defensa exterior. En dichos documentos se planteaba la disposición de la fuerza armada permanente de mar y tierra y de la milicia activa. En los textos: Primer Proyecto de Constitución Política de la República Mexicana, 25 de agosto de 1842; Segundo Proyecto de Constitución Política de la República Mexicana, 2 de noviembre de 1842; Bases Orgánicas de la República Mexicana, acordadas por la Honorable Junta Legislativa establecida conforme a los decretos de 19 y 23 de diciembre de 1842, sancionadas por el Supremo Gobierno Provisional con arreglo a los mismos decretos del día 15 de junio del año de 1843 y publicadas por bando nacional el día 14 del mismo; Estatuto Orgánico Provisional de la República Mexicana, decretado por el Supremo Gobierno, 15 de mayo de 1856. El concepto de seguridad interior fue omitido, para después recuperarse en la fracción sexta del artículo 86 del Proyecto de Constitución Política de la República Mexicana, 16 de junio de 1856, y en la fracción VI del artículo 85 de la Constitución Política de la República Mexicana, sancionada por el Congreso General Constituyente el 5 de febrero de 1857.

Es en el Proyecto de Constitución de Venustiano Carranza, 10. de diciembre de 1916, que el concepto de seguridad interior se incorpora en los siguientes términos: "Artículo 89. Las facultades y obligaciones del Presidente, son las siguientes... VI. Disponer de la fuerza armada permanente de mar y tierra para la seguridad interior y defensa exterior de la Federación". Las siguientes reformas constitucionales del artículo 89, en relación con la fracción VI, fueron durante la XXXIX Legislatura (1943-1946), donde se dio competencia al Ejecutivo para "disponer del Ejército, Marina de Guerra y Fuerza Aérea, para la preservación de la independen- 
cia y soberanía de la Federación”, y la duodécima reforma propuesta por el presidente Vicente Fox Quesada, en la que se incorporó, como antes se mencionó, dentro de la misma fracción VI la preservación de la seguridad nacional como una idea separada de la disposición de la fuerza armada permanente, en los términos vigentes. ${ }^{25}$

Del seguimiento histórico del concepto de seguridad interior es claro que no se trata de una derivación de la seguridad nacional, tal y como pretende quedar en la Ley de Seguridad Interior, sino de una definición constitucional con sentido propio, al que se le da su especificidad en los capítulos I, "Rebelión” (artículos 218-223), y II, "Sedición" (artículos 224-227), del título séptimo, "Delitos contra la seguridad interior de la nación", del Código de Justicia Militar, publicado en el t. LXXIX, núm. 52, del Diario Oficial el 21 de agosto de 1933.

Por lo anterior, queda evidenciado que no existen facultades para legislar sobre el concepto de seguridad interior, que está positivado desde 1824 en la Constitución, confundiéndolo con un concepto como el de seguridad nacional, incorporado al texto constitucional en 2004. Esto confirma que se trata de dos categorías jurídicas independientes, con su propia naturaleza, y con ello se acredita la inconstitucionalidad de la legislación sobre seguridad interior, porque el Congreso de la Unión no cuenta con competencia para ese propósito.

10) Se violan los artículos 49, 115, 116 y 124 de la Constitución. El empleo amplio de las fuerzas armadas por todo el territorio nacional, de manera permanente e impuesta por las autoridades federales del Poder Ejecutivo, constituye una transgresión del principio de división de poderes, debido a la ausencia de mecanismos de control legislativos y jurisdiccionales no previstos en muchas de las anteriores iniciativas, además de violarse el artículo 25 de la Convención Americana sobre Derechos Humanos, porque los ciudadanos carecen de un recurso efectivo para oponerse a esas decisiones.

25 Cruz Barney, Óscar, "Introducción histórica al artículo 89 de la Constitución”, Derechos del pueblo mexicano. México a través de sus Constituciones, México, Cámara de Diputados, LXIII Legislatura-SCJN-Tribunal Electoral del Poder Judicial de la Federación-CNDH-Senado de la República-INE-UNAM-Miguel Ángel Porrúa, 2016, t. IX, pp. 633 y ss. 
11) Se viola el principio de certeza jurídica. Las definiciones de seguridad interior en las iniciativas son vagas y abiertas, y cualquier problema de la vida nacional puede ser caracterizado como de seguridad interior y sujeto a la aplicación de la ley. En efecto caben tanto los supuestos de seguridad nacional como los supuestos de seguridad pública.

12) Se reprimirán las manifestaciones, en violación a los artículos 60. y 9o. de la Constitución. Alguna de las iniciativas establece que las manifestaciones no se considerarán amenazas a la seguridad interior si se realizan conforme a la Constitución. El problema jurídico consistirá en que la autoridad competente —el Ejecutivo Federal o el secretario de Gobernación- definirá qué es lo que se entiende por "manifestaciones conformes o no conformes a la Constitución", sin posibilidad que esa interpretación sea susceptible de control legislativo, judicial y constitucional.

13) Se viola el artículo 6o. de la Constitución, que establece el principio de máxima publicidad. Lo anterior, porque se considera que la información de seguridad interior, al ser de seguridad nacional, es reservada y sin que sea preceptivo cumplir con la prueba del daño, es decir, no existen garantías de transparencia ni de acceso a la información en la materia.

14) Se contravienen los tratados y las recomendaciones internacionales formuladas por los organismos internacionales sobre derechos humanos, que han señalado los riesgos de la militarización para los derechos humanos y, a su vez, el empleo de las fuerzas armadas de manera excepcional, en auxilio a las autoridades civiles y subordinadas siempre a estas últimas. ${ }^{26}$

15) La ley sirve para perpetuar un modelo que en doce años de aplicación de facto ha demostrado ser inefectivo para reducir la violencia del país y que, por el contrario, ha incrementado la inseguridad, las ejecuciones extrajudiciales, los desaparecidos, etcétera.

26 Véase entre otros, el comunicado del Alto Comisionado de Naciones Unidas para los Derechos Humanos (OACNUDH/REP203/2017) del 4 de diciembre de 2017; el pronunciamiento del INAI del 6 de diciembre de 2017 (INAI/411/17); el pronunciamiento de Artículo 19 efectuado el 5 de diciembre de 2017; las declaraciones del presidente de la Comisión Nacional de los Derechos Humanos, y las palabras de Miguel Álvarez Gándara - Premio Nacional de Derechos Humanos 2017_ y de la doctora Julia Carabias Lillo al recibir en 2017 la medalla Belisario Domínguez del Senado de la República. 
Además de lo anterior, en México existe una política presupuestal centralizadora que mengua, en materia de seguridad pública, las capacidades estatales y municipales. No obstante, en la actualidad tenemos más de 55,000 policías federales, 213,000 policías estatales y 134,000 policías municipales. Es verdad que no cuentan con los recursos, la profesionalización, la capacitación y los apoyos de las fuerzas armadas. La policía federal, sin embargo, cuenta con recursos elevados. Nuestra propuesta es que, en el marco del Estado federal, las policías de los tres órdenes de gobierno se capaciten, reciban la profesionalización debida, y que los recursos presupuestales se distribuyan adecuadamente entre las policías federales, estatales y municipales.

Como se observa, México sí cuenta con las policías, con diferencias entre ellos (profesionalización, capacitación y salarios), y con un número menguante de policías municipales.

Lo que define el número, la capacitación, los salarios y el armamento de los policías tiene que ver con la política presupuestal del país, que es profundamente centralista. Deliberadamente, el gobierno federal mexicano ha incrementado el gasto en armamento militar y en el número de efectivos militares. En parte, no tan relevante como el gasto militar, ha aumentado el gasto policial y el número de integrantes de la policía federal. En menor medida se ha preocupado por las policías de los estados. En los municipios se ha pauperizado la presencia policial. Francamente, por la vía de los recursos públicos se ha condenado a la desaparición de la policía municipal.

La observación hecha acredita que por la vía presupuestal podrían incrementarse los elementos, los salarios y la capacitación de la policía municipal, al igual que los integrantes de las policías estatales. Si hubiera una voluntad clara para fortalecer a los cuerpos policiacos del país, en todos los niveles de gobierno, ello podría ser posible en el corto plazo.

¿Qué lo impide? La creciente militarización del país, la subordinación de las policías a las fuerzas armadas y su relegación a cuerpos de seguridad secundarios con relación al poderío alcanzado por las fuerzas armadas. Sin embargo, la auténtica razón de esta postración es la injerencia de los Estados Unidos dentro de nuestros asuntos de seguridad doméstica, que han privilegiado la potenciación de las fuerzas armadas sobre las fuerzas policiacas. 


\section{III. ¿POR QUÉ LA SEGURIDAD EN UN ESTADO CONSTITUCIONAL \\ DE DERECHO CORRESPONDE A LA AUTORIDAD CIVIL \\ Y A LOS CIUDADANOS, Y NO A LAS FUERZAS ARMADAS?}

México tiene policías suficientes para atender las necesidades de seguridad pública en el país. Es verdad que las policías municipales y estatales requieren apoyo, pero mediante las políticas presupuestales adecuadas, y un decidido compromiso con la seguridad pública civil, ello podría lograrse en breve tiempo. El gobierno de Peña Nieto, al igual que el de Calderón, no lo ha querido realizar por los compromisos contraídos con el gobierno de los Estados Unidos. Se prefiere la militarización y las doctrinas de seguridad nacional de carácter bélico a la consolidación de la seguridad pública civil.

Un argumento que se suele emplear para impedir que las policías del país asuman su papel es el de la corrupción. Ésta existe también en las fuerzas armadas. La corrupción es un problema que tiene relación con el diseño de las instituciones. En México se requiere combatir la corrupción desde la Presidencia de la República y en todos los niveles; en especial, se debe lograr que los vigilantes - las autoridades competentes en materia anticorrupción - no dependan de los vigilados, como ahora ocurre con el nuevo Sistema Nacional Anticorrupción. La fórmula de combate a la corrupción consiste en otorgar mayores poderes de control ciudadano sobre las policías; emprender una lucha sin cuartel contra la impunidad vía los instrumentos de procuración y administración de justicia, y reconocer amplios mecanismos de democracia directa para que los ciudadanos supervisen, vigilen y auditen a las autoridades, incluyendo a las policías.

Así, el Decreto 156 de modificación constitucional adicionó la fracción XXIX-M al artículo 73 y reformó la fracción VI del artículo 89 de la Constitución para facultar al Ejecutivo a preservar la seguridad nacional — fue publicado en el Diario Oficial de la Federación el 5 de abril de 2004-. La modificación constitucional facultó al Congreso para expedir leyes en materia de seguridad nacional, estableciendo los requisitos y límites a las investigaciones. Se precisó que el Ejecutivo debe proteger la seguridad nacional. La reforma, además de fortalecer la facultad legislativa del Congreso con afectación a las legislaturas locales, otorgó al Ejecutivo, por encima de los otros poderes, órganos autónomos y niveles de gobierno, el deber de conservar la seguridad nacional, lo que constituye, desde nuestro punto de vista, una violación al principio de división de poderes (artículo 
49 de la Constitución), un daño grave al equilibrio que debe existir entre los poderes, y una reducción de los alcances del federalismo.

Lo más inaceptable es que esta reforma constitucional ha estado vinculada a la legislación secundaria que se desprende de ella y que pretende seguir derivándose de la misma: situar a las fuerzas armadas y al Consejo de Seguridad Nacional como garantes de la seguridad nacional y con poderes para determinar declaraciones de afectación a la seguridad interior sin participación del Poder Legislativo federal ni de las legislaturas locales $\mathrm{y}$, a su vez, para menoscabar los derechos fundamentales de los gobernados, suspendiéndolos de facto y de jure.

El riesgo de que se aprueben las reformas a la Ley de Seguridad Nacional hoy vigente nos recuerda a la Ley de Jurisdicciones española de 1905, que otorgó al ejército de ese país la custodia del patriotismo y que, al decir de muchos autores, desde Unamuno hasta Abellán, fue la causa, al colocar al poder militar por encima del civil, del militarismo español y de sus dos dictaduras en el siglo $\mathrm{XX}^{27}$

Nosotros consideramos que las fuerzas armadas no pueden ser las defensoras del Estado. En un Estado constitucional de derecho, los defensores del orden constitucional y de la seguridad nacional son los ciudadanos y las autoridades civiles. El defensor último y final es y debe ser el órgano de control de constitucionalidad. La guerra está proscrita en el derecho internacional y en el derecho interno de los Estados democráticos, salvo cuando es en legítima defensa. Aceptar la tesis de que las fuerzas armadas son las defensoras del Estado es admitir el punto de vista del jurista nazi Carl Schmitt, quien en su obra La defensa de la Constitución ${ }^{28}$ mantiene que son el jefe del Estado y las fuerzas armadas las que tutelan al Estado y defienden la Constitución. Nosotros preferimos el punto de vista de Hans Kelsen, quien sostuvo que son los tribunales constitucionales, todas las instituciones y los ciudadanos los que defienden al Estado y a la Constitución. ${ }^{29}$

Estamos de acuerdo con el punto de vista de Kelsen, porque el Estado de derecho, si lo es, sólo puede estar tutelado y defendido por los procedimientos democráticos y la racionalidad más plena del ordenamiento jurídico, así

27 Abellán, José Luis, Ensayo sobre las dos Españas. Una voz de esperanza, Barcelona, Península, 2011.

28 Schmitt, Carl, La defensa de la Constitución, Madrid, Tecnos, 1998.

29 Kelsen, Hans, ¿Quién debe ser el defensor de la Constitución?, Madrid, Tecnos, 2002. 
como por las de sus instancias garantes y por los ciudadanos. Si aceptamos que únicamente el Ejecutivo o las fuerzas armadas defienden la seguridad nacional y al Estado, estamos al borde de la dictadura, del rompimiento con el orden constitucional democrático. Por tal motivo, fue incorrecta la reforma a la fracción VI del artículo 89 de la Constitución de 2004, por sus tintes autoritarios no consecuentes con el Estado constitucional y democrático de derecho. El Ejecutivo no puede por sí ni ante sí ser el garante único de la seguridad nacional ni el encargado de preservarla o custodiarla.

La idea de un Estado en donde las fuerzas armadas juegan un papel destacado en la defensa del orden constitucional y la soberanía subvierte la lógica entera del Estado constitucional y democrático de derecho. Las fuerzas armadas son auxiliares en ese propósito y su papel debe estar constreñido por la propia Constitución, además de que deben estar subordinadas al órgano de control de constitucionalidad, al resto de los poderes públicos y a los propios ciudadanos.

El hecho de que las decisiones del Ejecutivo o de un Consejo de Seguridad Nacional no puedan ser controladas por el Poder Legislativo, el Poder Judicial, las entidades federativas, los municipios o los ciudadanos coloca a ese Poder por encima de los demás órganos y poderes del Estado. El conceder al Ejecutivo ese superpoder - preservar la seguridad nacional, y además, disponer de la totalidad de las fuerzas armadas - limita de entrada la soberanía popular y, como ya se dijo, hace nugatorios los principios de división de poderes y el federalismo.

Además, la reforma de 2004 a la fracción VI del artículo 89 de la Constitución fue y es muy peligrosa, porque, como lo hemos visto recientemente, se le interpreta sin tomar en cuenta el carácter sistémico e integral de la Constitución - la interpretación conforme- - Es decir, algunos, empezando por el titular del Ejecutivo actual, la leen o interpretan desvinculándola del procedimiento de suspensión de garantías; de la declaración de guerra que debe ser autorizada por el Congreso; de los mecanismos de intervención federal previstos en el artículo 119 de la Constitución; de la competencia en materia de seguridad pública que corresponde a las autoridades civiles, según el artículo 21 de la Constitución; de lo dispuesto en el artículo 129 de la Constitución, que indica que en tiempos de paz la competencia de las fuerzas armadas se constriñe a la disciplina militar y que el lugar de ellas reside en los cuarteles, y de las normas constitucionales sobre derechos fundamentales que prohíben actos de molestia que no estén fundados y motivados por una autoridad competente. 
La competencia de la fracción VI del artículo 89 de la Constitución ha sido mal interpretada y aplicada por el titular del Ejecutivo, pues se ha usado para militarizar el país y emprender una guerra de facto, y hasta ahora no de jure, en contra del crimen organizado. Tal estrategia bélica ha costado hasta ahora miles de muertos, miles de desaparecidos, así como un número inmenso de víctimas, huérfanos y desplazados. El gobierno federal, si quiere justificar jurídicamente la militarización y la guerra de facto emprendida, tendría forzosamente que recurrir en condiciones democráticas al procedimiento de suspensión de garantías del artículo 29 de la Constitución, a una declaración de guerra autorizada por el Congreso, en los términos del artículo 73, fracción XII, de la Constitución, o al procedimiento, al menos, previsto en el artículo 119 de la Constitución, relativo a la intervención federal en las entidades federativas.

La militarización en curso, que se fundamenta por el titular del Ejecutivo en la fracción VI del artículo 89 de la Constitución reformada en 2004, violenta los derechos fundamentales al permitir los retenes, los cateos, las detenciones y las intervenciones telefónicas, entre otras acciones, a cargo de las fuerzas armadas. Éstas han asumido atribuciones de facto que no les corresponden, como son las relacionadas con la seguridad pública, la prevención, la persecución, la investigación y la sanción de los delitos, que sólo competen constitucionalmente a los jueces, al Ministerio Público y a la policía, según lo establece el artículo 21 de la Constitución.

La competencia de la fracción VI del artículo 89 de la Constitución ha intentado indebidamente justificar que el Ejecutivo tenga poderes extraordinarios para militarizar al país, violando el principio de división de poderes y el pacto federal. La militarización que vivimos no permite la participación ciudadana efectiva en las políticas y en el diseño de la seguridad nacional y pública, pues no existe a la fecha un solo mecanismo de democracia participativa ciudadana, de transparencia o de rendición de cuentas en las instituciones de las fuerzas armadas, en el Ejecutivo o en los esquemas gubernamentales hoy vigentes, en donde los ciudadanos se involucren de verdad en las funciones de seguridad pública y nacional.

El papel del Congreso de la Unión se ha obviado por el Ejecutivo a través del abuso de la interpretación sui generis que hace de la fracción VI del artículo 89 de la Constitución. Los actos de militarización del Ejecutivo constituyen auténticas resoluciones de estados de excepción o de sitio (suspensión de garantías), que para nada cumplen con el procedimiento del artículo 29 de la Constitución. 
Además, se entiende, por los voceros del gobierno, que la seguridad es del Estado o, peor aún, del gobierno en turno, y se olvida que cualquier concepto de seguridad jurídica, pública o nacional, debe estar orientada y justificada en los derechos fundamentales de los gobernados. Ningún concepto de seguridad pública o nacional debe colocarse por encima de los derechos humanos y para despreciar la vida, la libertad, el debido proceso, etcétera, de los ciudadanos a través de una lógica de guerra que destruye el tejido social y deslegitima a las instituciones.

La seguridad debe ante todo ser soberana, es decir, decidida por los ciudadanos de este país, de preferencia a través de mecanismos participativos, como el referéndum. La seguridad nacional no debe responder, tal como ahora responde, a los intereses de los Estados Unidos. Esta guerra no declarada constitucionalmente contra el crimen organizado tiene su origen en los acuerdos de la ASPAN, en la Iniciativa Mérida y en otros acuerdos de palabra entre los jefes de Estado y de gobierno de los Estados Unidos y México. Nunca ha sido ratificada por el Senado de la República a través de un tratado, lo que implica que todos esos acuerdos internacionales devengan en anticonstitucionales.

Mediante la estrategia fallida y la mala interpretación constitucional de la fracción VI del artículo 89 de la Constitución, los gobiernos de Calderón y Peña Nieto han buscado legitimarse infructuosamente en el ejercicio del poder, y en este sexenio se ha abusado del concepto de seguridad nacional y de la ley secundaria en la materia para espiar, perseguir y reprimir movimientos sociales.

La seguridad nacional es un concepto derivado de la Guerra Fría, imaginado por teóricos y políticos norteamericanos, para mantener áreas de influencia de los Estados Unidos en el mundo, y evitar con ello la propagación en aquella época del socialismo real en esas regiones. Es, por tanto, una categoría teóricamente caduca que ha sido sustituida por las de seguridad humana y ciudadana. Su finalidad estribaba en mantener condiciones de estabilidad y gobernabilidad en los Estados Unidos, previniendo y rechazando las amenazas militares de otros Estados (nivel externo) y para enfrentar y prevenir el terrorismo, los riesgos medioambientales y fenómenos sociales (nivel interno), como la inmigración masiva hacia las fronteras norteamericanas; en los últimos años se ha empleado para rechazar al crimen organizado, principalmente el que tiene que ver con el narcotráfico.

El concepto de seguridad nacional en México es importado y promovido en nuestro país para garantizar, sobre todo, la seguridad de los Estados Uni- 
dos. Es por ello necesario que se modifique la fracción VI del artículo 89 de la Constitución, para que no seamos los policías de la frontera sur de los Estados Unidos y para que el Ejecutivo no siga haciendo, a través de una indebida interpretación de esta facultad, fraude a la Constitución y ejerciendo poderes metaconstitucionales, que son inaceptables en una democracia y en un Estado constitucional y democrático de derecho.

Adicionalmente a lo anterior, la guerra es la negación del derecho, y por eso, su existencia y, además, su reconocimiento jurídico absoluto, sin matices, son muestras fehacientes de que el Estado salvaje aún prevalece. Desde el bellum justum (guerra justa) hasta hoy con la llamada "guerra contra el crimen organizado", la guerra constituye un problema para la existencia del Estado de derecho y la conciencia del desarrollo civilizado y democrático de los pueblos.

Norberto Bobbio ha explicado que "la historia de la evaluación moral de la guerra puede dividirse, por lo menos en lo que respecta a las obras relativamente más cercanas, en tres fases: la del bellum justum, la de la raison d'etat y la de la guerra como crimen". ${ }^{30}$ En ese contexto, desde el derecho, la guerra se ha considerado, en primer término, como un posible medio de justicia; en segundo término, como una prerrogativa de la soberanía, y tercer término, que es el contemporáneo, como un crimen. La guerra es hoy en día un crimen contra la humanidad.

A su vez, desde la ciencia política se ha dicho que la guerra es la continuación de la política por otro medio (von Clausewitz). Según la doctrina tradicional que se ha construido en torno al fenómeno colectivo de la guerra como objeto de estudio, varios son los elementos constitutivos que ayudan a determinar su concepto: a) una actividad militar; b) un elevado grado de tensión en la opinión pública; $c$ ) la entrada en vigor de normas jurídicas atípicas, $y$, por cierto, difícilmente democráticas, respecto de las que rigen en el periodo "de paz", y d) una progresiva integración política dentro de las estructuras estatales beligerantes. En la caracterización de la guerra, ésta "adopta al mismo tiempo la forma de una especie de conflicto, de una especie de violencia, de un fenómeno psicológico-social, de una situación jurídica excepcional y de un proceso de cohesión interna en algunas ocasiones". 31

30 Bobbio, Norberto y Matteucci, Nicola, Diccionario de politica, México, Siglo XXI Editores, 1988, t. I, p. 766.

31 Ibidem, p. 762. 
Por ello, Kant no dudó en expresar que la guerra es intrínsecamente antidemocrática, pues el pueblo obligado a hacerla no sólo pierde su soberanía, sino su propia dignidad humana y civil. ${ }^{32}$ Esto es precisamente porque se trata de un estado de excepción, en el que se coloca en extrema vulneración a grandes grupos humanos; en efecto, la guerra debe ser la última ratio, el último recurso que debe utilizar un Estado que se pretenda civilizado. Por eso es que la guerra, como nos dice Luigi Ferrajoli,

...por sus intrínsecas características destructivas, no admite hoy justificaciones morales y políticas. Es de por sí un mal absoluto, con respecto al cual los viejos límites iusnaturalistas de la guerra justa resultan ahora insuficientes, al haber quedado desbordados todos los límites naturales a sus capacidades destructivas. Por sus propias características, la guerra es una regresión al estado salvaje o de naturaleza del homo homini lupus. Con la diferencia de que la sociedad salvaje de los Estados no es una sociedad de lobos naturales, sino una sociedad de lobos artificiales, es decir, de esos "hombres artificiales", como los llamó Hobbes, que son los Estados creados por los hombres para tutela de sus derechos y que hoy amenazan con escapar a su control y revolverse contra sus creadores como máquinas artificiales capaces de destruirlos. ${ }^{33}$

El espíritu de prohibir el uso de la fuerza y, por ello, considerar como último recurso la guerra fueron aspectos que incorporó desde su constitución la Organización de las Naciones Unidas en su Carta. En el preámbulo, la Carta de las Naciones Unidas se pronuncia por defender la paz, expresando que los Estados miembros se comprometen "a preservar a las generaciones venideras del flagelo de la guerra... a unir nuestras fuerzas para el mantenimiento de la paz y la seguridad internacionales, a asegurar, mediante la aceptación de principios y la adopción de métodos, que no se usará; la fuerza armada sino en servicio del interés común". Así pues, como premisa mayor, la Carta de Naciones Unidas prohíbe el uso de la fuerza, de conformidad con su artículo 2o., párrafo 4: "Los Miembros de la Organización, en sus relaciones internacionales, se abstendrán de recurrir a la amenaza o al uso de la fuerza contra la integridad territorial o la independencia política de cualquier Estado, o en cualquier otra forma incompatible con los Propósitos de las Naciones Unidas".

La guerra así, en el marco jurídico internacional, sólo está permitida cuando se lleva a cabo en legítima defensa, lo cual explica que actualmen-

32 Ferrajoli, Luigi, Democracia y garantismo, Madrid, Trotta, 2008, p. 366.

33 Ferrajoli, Luigi, Las razones jurídicas del pacifismo, Madrid, Trotta, 2004, p. 33. 
te se considere a la guerra como un crimen contra la humanidad y, por ello, que cualquier refugio en la misma se pueda considerar contrario a la moral y al derecho. ${ }^{34}$

Nuestra tesis se inscribe en la formulación de la Carta de las Naciones Unidas, en el derecho internacional de los derechos humanos y en los principios de nuestra Constitución. Es imprescindible reformar la fracción VI del artículo 89 de la Constitución. La modificación debe hacerse para derogar que el titular del Ejecutivo tenga la facultad de preservar la seguridad nacional, pues ésta corresponde preservarla y garantizarla a todos los ciudadanos y a la totalidad de las autoridades del Estado, y para que el presidente pueda disponer de la totalidad de la fuerza armada permanente, o sea, del ejército, de la armada y de la fuerza aérea, para la defensa exterior del país y, a nivel interno, en los casos de suspensión de derechos y garantías, intervención federal, de amenazas o riesgos medioambientales, campañas de salud y educativas, en donde la autoridad militar estará subordinada al Ejecutivo, al Congreso de la Unión, al Poder Judicial federal y al resto de los niveles de gobierno y órganos constitucionales previstos en la Constitución. Las fuerzas armadas no pueden intervenir en funciones vinculadas a la seguridad pública o para prevenir o reprimir movimientos sociales, y mucho menos violentar derechos fundamentales de los gobernados. ${ }^{35}$

\section{CONCLUSIONES}

Como medidas alternativas a la militarización que se propone con la aprobación de la Ley de Seguridad Interior, y para salvaguardar la seguridad y reducir los índices de violencia, consideramos que, además de profesionalizar y capacitar a las policías del país, es importante:

1) Establecer un plan de pacificación nacional que involucre a todos los sectores sociales, económicos y políticos del país, a las víctimas y ofendidos de los delitos, entre otros, para aprobar medidas legislativas — ley de amnistía-, jurisdiccionales — justicia tran-

34 Bobbio, Norberto y Matteucci, Nicola, op. cit., p. 769.

35 Wolkmer, Antonio Carlos, Teoría crítica del derecho desde América Latina, México, Akal, 2017, p. 279. 
sicional $-{ }^{36} \mathrm{o}$ administrativa — respaldar presupuestalmente a los municipios - que permitan la reconciliación nacional.

2) Garantizar, mediante su exigibilidad y justiciabilidad, los derechos económicos, sociales, culturales y ambientales de la población. La educación, el trabajo y la salud son los principales antídotos en contra del crimen, la violencia y la inseguridad.

3) Derogar las facultades del Congreso de la Unión para aprobar leyes en materia de seguridad nacional. La seguridad nacional, como es entendida por la ONU y no por la vieja y nueva doctrina de la seguridad nacional de los Estados Unidos, es una tarea que corresponde a los ciudadanos y a todas las autoridades, fundamentalmente a las civiles, de acuerdo con sus competencias. En una democracia constitucional, el último garante de la seguridad nacional es el propio pueblo y la Suprema Corte de Justicia de la Nación, y no las fuerzas armadas.

4) Rechazar la guerra ofensiva. La Constitución de la República sólo permite la guerra exterior en legítima defensa.

5) En periodos de paz, las fuerzas armadas en el ámbito interno tienen las siguientes facultades: $a$ ) en situación de suspensión de derechos humanos y garantías — artículo 29 de la Constitución-; b) para aplicar la garantía federal en los términos del primer párrafo del artículo 119 de la Constitución, y c) en los supuestos de las fracciones IV, V y VI del artículo 76 de la Constitución.

6) Los integrantes de las fuerzas armadas de la República deben regresar, en los términos del artículo 129 de la Constitución, a sus cuarteles, sin que puedan atender tareas de seguridad pública ni ninguna otra que no esté comprendida en los supuestos de la fracción VI del artículo 89 constitucional.

7) Las autoridades competentes, en los tres niveles de gobierno, deben reasumir sus competencias en materia de seguridad pública. La autoridad que no pueda reasumir sus competencias íntegramente, deberá comunicar esa circunstancia al titular del Poder Ejecutivo Federal, para que éste inicie en la entidad federativa correspondiente el procedimiento de suspensión de derechos humanos y ga-

36 Olasolo, Alonso, Derecho internacional penal, justicia transicional y delitos transnacionales: dilemas politicos y normativos, Valencia, Tirant lo Blanch, 2017; Berdugo Gómez de la Torre, Ignacio, La justicia transicional en Brasil. El caso de la guerrilla de Araguaia, Salamanca, Ediciones Universidad de Salamanca, 2017. 
rantías, además de iniciar con respecto al gobernador y alcaldes los procedimientos de juicio político y de responsabilidades que correspondan.

8) Se deben declarar nulos, por inconstitucionales, los acuerdos interinstitucionales en materia de seguridad nacional, interior y pública suscritos con los Estados Unidos de América. Dichos acuerdos no pasan por la aprobación del Senado, aunque la legislación secundaria permita la suscripción de este tipo de acuerdos, según el artículo 2o., fracción II, de la Ley sobre Celebración de Tratados.

9) Se debe constituir una comisión de la verdad, integrada por cinco titulares electos por los ciudadanos, para investigar los actos y omisiones que impliquen violaciones a los derechos humanos respecto a las conductas de los responsables civiles y militares, incluyendo a los presidentes de la República, que con motivo de la actuación de las fuerzas armadas en tareas de seguridad pública o en la realización de funciones relacionadas con la prevención, la contención, la investigación y la persecución de los delitos vinculados al crimen organizado, hayan cometido los integrantes de las fuerzas armadas en contra de personas, víctimas u ofendidos, ajenas al crimen organizado, así como en contra de supuestos o integrantes del mismo.

10) La despenalización de los delitos vigentes que estén relacionados con el consumo, el uso, la comercialización y el tráfico de todas las drogas.

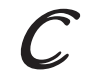

Fecha de recepción: 29 de noviembre de 2017.

Fecha de aceptación: 25 de julio de 2018. 